DOI 10.37882/2500-3682.2022.01.11

\title{
НА ГРАНИ СРЫВА: НАУКА И ГУМАНИЗМ
}

\section{ON THE VERGE OF FAILURE: SCIENCE AND HUMANISM}

\section{K. Salyamov}

Summary: The article demonstrates the existence of a special line of philosophizing - the line of common sense. This line is contrasted with the other two, namely the Greek and the Eastern. It is argued that the distinguishing feature of the line under study is the concept of common sense. The work traces the history of the development of this philosophical term. For the most part, common sense was developed along the lines of the pragmatic tradition, but it was not limited to it. It is shown that there are two ways of interpreting common sense: scientific-critical and humanistic ways. To bridge the gap between them, the author offers his own version of the consideration of common sense.

Keywords: common sense, philosophical term, reality.

\author{
Салямов Камиль Маратович \\ Московский государственный университет \\ им М. Ломоносова \\ kamasalyamov@gmail.com
}

Аннотация: В статье демонстрируется существование особой линии философствования - линии здравого смысла. Эта линия противопоставляется другим двум, а именно Греческой и Восточной. Утверждается, что отличительной чертой исследуемой линии является концепт здравого смысла. В работе прослеживается история развития этого философского термина. Здравый смысл по большей части был развит в русле прагматической традиции, однако ею не ограничивался. Показывается, что имеется два пути толкования здравого смысла: научно-критический и гуманистический способы. Для преодоления пропасти между ними автор предлагает свой вариант рассмотрения здравого смысла.

Ключевые слова: здравый смысл, философский термин, реальность.

на английский можно перевести как "essence", а на русский как "сущность". Схоласты называли это "essentia", а Платон "оusia" (oúбía). Однако онтология, которая скрывается под этими терминами различается [22, c.43-44]. В то время как греческая ousia выражало то, что подлинно есть (сущность сущего или суть всего существующего), схоласты, а по мнению автора и все представители Восточной линии, рассматривали свою essentia как бытие вещей. Так, например, Фома Аквинский пишет:

"Итак, остается только, что имя "сущность" обозначает в составных субстанциях то, что составлено из материи и формы. .... С этим согласуется и умозаключение: бытие составной субстанции не есть бытие только формы или только материи, но бытие того, что из них составлено. Но сущность есть то, в соответствии с чем, как говорится, существует вещь." [22, с.143].

Именно в этой разнице и высматривается Восточная линия. Они пытаются найти не подлинность (суть) вещей, но некоторое чудо, благодаря кому сущее возникло. Греки же, в частности Аристотель, не отделяли бытие от сущего, то есть сущее и есть свое собственное бытие и никакого "чуда" его привнесения не требует [22, с.47].

Важность этого момента довольно принципиальная, ведь если бы такого разделения не проводилось, то не было бы смысла говорить о Боге. Собственно, сама схоластика как философская школа и возникла для того, чтобы проинтерпретировать Аристотеля на христианский манер. 
Восточная линия в Азии (в Индии, Китае) ярко прослеживается в учениях таких мыслителей как Будда (Сидхарта Гаутама) с его учением о нирване; Лао-Цзы с его безымянным; и наконец, Конфуций с воззрением на особое начало человека "жэнь".

Тем не менее, на западе Восточной линии пришлось не без препятствий. С появлением таких людей как Коперник и Галилей стала распространятся идея о разделении науки и религии, тем самым возрождая греческую традицию. Это тенденции оформилась в Новое время под термином секуляризация. Однако проблем от того меньше не стало. Каким же образом наука открывает истины? Одни участники дискуссии (эмпиристы) считали, что наука должна опираться на опыт и открывать истины (подлинную реальность) путем индукции. Другие (рационалисты) были убеждены, что истина открывается не таким способом, но благодаря идеям разума, данными самим Богом. Эмпиристов и рационалистов можно условно рассмотреть, как тех, кто тяготел больше к Греческой линии (эмпиристы) и тех, кого впечатляли схоласты (рационалисты).

Традиционно считается, что данный спор был решен И. Кантом, однако на взгляд автора это не так. Кёнигсбергский мыслитель транспонировал пространство, в котором шла дискуссия от внешнего мира к внутреннему, перенося тем самым и проблемы. Кантовские вещив-себе стали недоступными греческими сущностями, а все доступное, вещи-для-нас, без привнесения им бытия от человека сами суть ничто. Таким образом, кенигсбергец нашел некоторый способ примирения двух линий.

Такой подход хоть и принес плоды в свое время, но является абсолютно нерелевантным касательно современного состояния науки. Ведь раз науке доступны лишь феномены (вещи-для-нас), знание которых основано на определенных a priori, то возникает вопрос с квантовой физикой. Как объяснить корпускулярно-волновой дуализм микроскопических объектов? Да и вообще, каким образом мы смогли открыть мир частиц?

Принимая во внимания собственную дистинкцию, К. Поппер не может однозначно отнести И. Канта ни к эссенциалистам, ни к номиналистам. Он, собственно, так и пишет:

"Даже те, кто не любит во всем следовать Канту (к их числу я отношу и себя), вынуждены согласиться с ним в том, что разум исследователя “должен заставлять природу отвечать на его вопросы, а не тащиться у нее словно на поводу.

Но "коперниканский переворот" Канта несет в себе и другой смысл, указывающий нам на противоречивость (двойственность) кантовской позичии. ... [Кант - прим. С. К.] показал, что в определенном смысле наш мир вращается вокруг нас, что мы те, кто, по меньшей мере создает открываемый нами в мире порядок" [15, с. 49-50]

К. Поппер замечает попытку Канта в том, что выше было названо как примирение греческой и восточной линии. Но ему такой ход кажется противоречивым, изза его узкой историко-философской классификации.

В связи с этим, в данной работе предлагается рассмотреть иную линию мышления - линию здравого смысла. Согласно этому взгляду, не существует никакой подлинной реальности, сокрытой от наших глаз и также не существует никакого чуда и божественных идей. Реальность здравого смысла не имеет ничего общего с такими понятиями как схоластическое бытие (quod est) и/или греческое сущее (oúoía/esse). Но вот что именно она такое - вопрос, который исследуется в данной работе.

\section{ЗАравый смысл}

По мнению автора, явным основателем этого направления стал Т. Рид - зачинатель т.н. Шотландской школы Здравого смысла. Т. Рид считает, что существует реальность, которая познается явным образом благодаря здравому смыслу. Здравый смысл он рассматривает в двух аспектах: а) как повседневное мышление обычного нормального человека; и b) как врожденные верования, принципы. Взгляд через ракурс пункта (а) связан не с личными взглядами шотландского философа, но с общей интуицией народов Европы о том, что внутренне чувство бывает нормальным и ненормальным, которую разделял и младший современник Т. Рида И. Кант [12, с.395-936]. Понять ее просто, если взглянем на английский перевод, а именно "common-sense", который на русский буквально переводиться как "общее чувство". Common-sense своим корнями идет от средневекового commonis-sensus (лат.), свою очередь опирающаяся на идеи Аристотеля, где пяти известным внешним органом чувств соответствует пять внутренних способностей ума, которые свидетельствует нормальное интеллектуальное состояние человека (Johansen). Ключевым же, является тезис (b), который шотландский философ выдвигает после выхода "Трактата о человеческой природе", где Д. Юм выдвигает неприемлемый с точки зрения Т. Рида скептицизм [19, с.89]. Именно в этом тезисе и корениться ключевое отличие позиции Т. Рида от И. Канта. Его аргумент, на который будут опираться все последующие анализируемые в статье авторы, тезисно формулируется так:

1. Главное допущение любого скептицизма - идея о том, что уму доступны лишь идеи, формы вещей, а не сами вещи (Р. Рорти будет называть это идеей "идей").

2. Получается, что уму не даны вещи сами по себе (из 1), что введет к познавательной пропасти (epistemological gap). Т. Рид в инвективной форме назвал этот феномен "занавесом идей". 
3. Следовательно, любого рода скептицизм оправдан (занавес может быть как полупрозрачный, так и абсолютно не прозрачный).

Выходом соответственно становится отрицание допущения о существования идей и выдвижения здравого смысла как набора априорных верований (аналог кантовских априори), которые позволяют нам быть уверенным в том, что мы воспринимаем. Повседневными практиками уже все расставлено так как нужно. А здравый смысл является лишь манифестацией этой правильности посредством обыденного языка.

Проблема с таким выводом возникает, как только мы задаемся вопросом о том, как функционирует наука и откуда она берется. Любимая шотландскому философу Ньютоновская физика становится результатом народной мудрости, в то время как именно эта народная "мудрость" долгое время оставалась, да и в какой-то степени остается оппозиционной к научному познанию. Философская линия "Платон-Декарт-Локк-Юм" потому ведь и существует, что порой народная мудрость говорит что-то очень странное и сомнительное. Именно поэтому, прав был Ч. Пирс, когда писал, что Т. Рид упустил остроту критикуемой им философии, однако пафос его идеи кажется автору (и Ч. Пирсу) верным и требует тщательной реконструкции.

\section{Критический зАравый смысл}

Опираясь на это аргумент, но решая проблему редукции здравого смысла к повседневному мышлению, Ч. Пирс строит свою теорию Критического Здравого смысла (Critical common-sense). Эта идея отличается от шотландской школы по следующим параметрам:

i) Верования могут изменяться со временем. [13, c.187-188]

ii) “... некритически несомненное есть неизменно смутное (vague)." [13, с.189] Этот тезис означает, что те верования, про которые говорит Т. Рид, пригодны лишь для примитивного образа жизни. В науке же они никак не могут быть использованы, так как не являются очевидными.

iii) Ч. Пирс признает достоинство и всю глубину юмовского скептицизма. Юм по Пирсу сомневается не во всем мире, но лишь говорит о том, что большая часть наших познавательных утверждений есть лишь гипотезы [13, с.242-244]. Причем гипотезы в том смысле, в котором Ньютон писал: “Гипотез [я] не измышляю”. Юм помог нам избавиться от схоластического "чуда". В этом смысле Ч. Пирс рассматривает юмовский скептицизм как инструмент проверки несомненности провозглашенных убеждений [13, с.198].

В связи с этими положениями Пирс как раз и разрабатывают идею прагматицизма. Так как мы не можем точ- но знать, что за верования лежат в нашей основе, то мы должны критически контролировать свое мышление:

"Ведь конечную цель исследования интеллектуального содержания символов Прагматицизм видит именно в раскрытии понятия рачионального поведения, то есть поведения, подчиненного самоконтролю [13, с.186].

Проблемы возникают тогда, когда мы ставим вопрос об объективности и субъективности. Ведь по Ч. Пирсу объективность все-таки есть, просто если Т. Рид утверждал, что она дана нам явно и априорно, то для американского философа она скрыта за туманностью (vagueness), которые нужно критическим образом сдуть. Наука, как и философия, хоть и подвержена ошибкам (fallible), но к истине стремится и приближается. Наука имеет прогресс, который выражается в достижении определенного консенсуса, не смотря на различные методы. Соответственно вопрос: что представляет из себя такая истина и как именно ученные к ней приближаются?

Для положительного ответа на эти вопросы с учетом своего собственного учения, Ч. Пирс развивает свою версию схоластического реализма [13, с.199-200]

Под схоластическим реализмом Ч. Пирс понимает утверждение о том, что общие понятия и научные законы (generals and laws) существуют реально, где реальность означает независимость от человека.

Для доказательства своей позиции американский философ осуществляет два важных хода: і) переосмысление объективности; іi) введение трех модусов реальности. Поясняет он их на примере с алмазом. Представим себе ситуацию, в которой алмаз, выкристаллизованный на ватной подушке, успел сгореть до того, как до него смогло достать какое-то отточенное лезвие. Вопрос: был ли алмаз реально тверд? Ответ Ч. Пирс безусловно положителен. Так как прагматицист не спрашивается о том, что произошло на самом деле, но лишь о том каким образом мы бы с ним взаимодействовали, если мы его классифицируем как алмаз. Это, собственно, и есть максима прагматицизма, то есть интеллектуальное содержание любого понятия заключается в том, какие мыслимые условия своего проявления на практике оно имеет. Таким образом, прагматицист не мыслит лишь в рамках действительного, но и в рамках модусов возможности и необходимости. Ведь тот же алмаз, дабы быть алмазом в действительности, должен иметь определенные условия таковой своей классификации. При этом эти условия могут быть как множественные и неопределенные, то есть иметь несколько вариантов (модус возможностей); этот вариант также может быть лишь один, в такой случае он необходим. Соответственно, возвращаясь к нашему алмазу, Ч. Пирс заключает, что нас не интересует конкретно данный алмаз, ибо любой конкретный алмаз есть просто предмет классифицированный как алмаз, а это значит, что вот 
этот алмаз, коль сколько он алмаз, вне зависимости от того, что с ним действительно произошло, является реально твердым, согласно общему понятию алмаза, которому он соответствует. Если бы мы до него все-таки успели до коснуться, то убедились в том, что он тверд, если он действительно алмаз, иначе он просто не алмаз и мы совершили ошибку в классификации.

Проще всего понять рассуждения Ч. Пирса на другом примере из другого сочинения, в котором он более детально развивает свою триаду, а именно на примере с силлогизмом. Есть большая посылка (модус возможности). Пример, все люди <когда-то> умирают. Умирание здесь есть видимая характеристика всех людей. Есть и меньшая посылка (модус действительности): Енох есть человек. Следовательно, Енох <когда-то> умирает (реальная необходимость) [14, с.170]. Причем этот закон является реальным в том смысле, что он возник независимо от нашей субъективности.

\section{Гуманистический зАравый смысл}

Модификация концепта здравого смысла Ч. Пирсом связанно не столько с защитой позиции Шотландской школы, сколько с обоснованием науки. Сам американский мыслитель заявлял, что строит научную метафизику, сводя философию к философии науки. Не секрет, что тема обоснования науки тогда уже начинала набирать популярность, особенно это связанно с проблемой индукции. Этой проблемой также занимался Джон Стюарт Милль, с работами которого ч. Пирс был непременно знаком. Однако, если Милль пытается решить проблему индукции, оставаясь в пределах того дискурса, в котором эта проблема возникла, то Ч. Пирс критикует ее основания, коим ему виделся номинализм - учении о том, что научные законы не существуют реально.

Тем не менее, научное мировоззрение не было "руководящим принципом" для другого отца основателя американского прагматизма - Уильяма Джеймса. Если Ч. Пирс пытался защитить науку, в частности логику и математику, то У. Джеймс - человека. Так, он пишет:

"Человек теперь не законодатель природы, он послушный исполнитель. ... Романтическая спонтанность и мужество исчезли, мироощущение стало материалистично и уныло" [20, с.7]

Реализм Ч. Пирса универсализирует не только научное мировоззрение, но человека, что неприемлемо для У. Джеймса. Для последнего не могут существовать универсальные переживания, переживания различаются не только у людей, но и внутри одного потока сознания. Даже единичный человек не испытывает одинаковые эмоции и переживания. Поэтому, по мнению автора данной работы, У. Джеймс основал номиналистическое крыло прагматизма вопреки Ч. Пирсу.
Главное различие между двумя философами заключалось в трактовке истины и, соответственно, здравого смысла, история которого является центральной для данной работы. И для того, и для другого истина является некоторым верованием, принципом действия. Однако для Ч. Пирса это верование будет прослеживаться у всех с необходимостью. Какие бы вы факты не выделяли, как бы разнообразно вы не смотрели на мир, будут иметься такие верования, которые существуют с необходимостью (законы). [20, с.11] В то время как для У. Джейма истина конструируется нашими же переживаниям, которые индивидуальны для каждого, а не всеобщие:

"мысли (составляющие сами лишь часть нашего опыта) становятся истинными ровно постольку, поскольку они помогают нам приходить в удовлетворительное отношение к другим частям нашего опыта" [20, с.41]. Последовательным образом усматривается и разница между их понятием о здравом смысле. Для ч. Пирса он представляет собой набор изменяемых верований, причем изменяемых в сторону истины, так как эти верования мы подвергаем критике.

В оппозицию критическому здравому смыслу У. Джеймс строит гуманистический здравый смысл, понимаемый им как стадия равновесия развития человеческого духа. Человек не является отделенным по Джеймсу от человечества, он включен в человеческое общежитие и усваивает общие методы мышления. Наука в этом смысле может даже противоречить здравому смыслу так как диктует нам такой опыт, который мы никак не переживаем и не мыслим. Иначе говоря, гуманистический здравый смысл разрушает бинарную оппозицию объективное-субъективное, снижая роль эпистемологии до минимума.

Прагматизм У. Джеймса был не то, чтобы, методом или философской школой, но образом жизни (way of life) отождествляемый с американским.

\section{"^евые" неопрагматисты}

Так как распространением самих взглядов Ч. Пирса занимался У. Джеймс, то именно номиналистическая, или левое крыло прагматизма было распространенно больше всего. Главными представителями его можно назвать - Дж. Дьюи и Р. Рорти.

Впитав в себя онтологическое разделение М. Хайдеггера и лингвистический поворот Л. Витгнештейна в симбиозе с позицией У. Джеймса и Дж. Дьюи, Р. Рорти доводит левый прагматизм до абсолютного релятивизма и приходит к нивелированию эпистемологии.

Его аргумент можно представить следующим образом:

1. Опираясь на Л. Витгенштейна [9, с.174], он считает, что язык есть начало и причина нашего осознаваемого феноменального опыта. Я могу осознавать 
и видеть лишь то, что дано мне в языке.

2. Не существует нейтрального языка, который позволил бы нам выбирать язык объективным образом. Р. Рорти назвал эту идею иронизмом.

3. Следовательно, вся реальность и наши переживания конструируются нашим словарем и все, что нам остается - это сравнивать языки по полезности. Язык как инструмент - вот тезис Р. Рорти.

В связи со своей привязанностью к Л. Витгенштейну В плане интерпретации феноменального опыта, Р. Рорти решает свои проблемы схожим образом. Сам австрийский философ видел главным препятствием своим идеям проблему цветообозначения. Эта проблема настолько смущала его, что он написал целую работу на эту тему: "Заметки о цвете". Вкратце его решение таково: “Кто не может играть в данную игру, [в частности игру цветообозначения - прим. С.К.] не обладает данным понятием". [11, с.154] Иначе говоря, если какое-то общество не имеет каких-либо правило для обозначения цветов, то у них нет и представления о цвете. Р. Рорти продолжил эту интуицию. В первой части его книге “Философия и зеркало природы" американский философ приводит пример антиподов - народа, у которого в языке отсутствуют понятия о внутренних переживаниях и [18, с.71]. Вместо того, чтобы использовать такие понятия как "боль" или "красное", они прибегали к терминологии биохимии и неврологии. Так, например, когда их младенцы тянулись к горячей вещи, матери кричали: “Она будет стимулировать С-волокна!" [18, с.723]. Важнейшим для данной работы следствием прагматизма Р. Рорти является то, что наука превратилась лишь в особого рода практику использования языка. Ее теории и концепт истины - результат установки языка, то есть конвенция. [3].

Релятивизм Р. Рорти активно атаковался его коллегой и другом X. Патнэмом с его концепцией реализма.

Х. Патнэм критикует Р. Рорти за его мнимый прагматизм. По мнению первого Р. Рорти неправильно проинтерпретировал классиков прагматизма, что в классическом прагматизме науке все-таки придается большее значение, чем просто какой-то языковой практике. Х. Патнэм справедливо замечает, что позиция Р. Рорти - это позиция скептика, против которого, собственно, и стоит прагматизм в любой его форме.

Однако само решение проблему Х. Патнэмом не сильно отличается от Рорти. Несмотря на то, что он называет свою идею метафизическим реализмом, реализм здесь понимается в левой форме прагматизма, то есть со стороны того, кого Ч. Пирс называл номиналистом. Его идея такова: у нас действительно не может быть прямой возможности обнаружения истины, однако это не значит, что нам нужно ее отбрасывать. Истина с большой буквы нужна нам как идеал, к которому стремится наука, иначе прогресс будет невозможен. [6].
В итоге получается, что Х. Патнэм так и не решает проблему релятивизма, так как его позиция имеет общие корни с рортианской. [10].

\section{"Правые" неопрагматисты}

Правая линия прагматизма, представленная в лицах последователей принципов Ч. Пирса [16], является линией "рыцарей науки".

Несмотря на то, что К. Поппер не является наследником идей Ч. Пирса, так как на него никак не опирался, его идеи вполне синхронизируются с Ч. Пирса. Совпадение идеи между ними было показано в работе [5]. Автор данной работы приводит множество фундаментальных точек совпадения. Так, например, и тот и другой принимали фаллибилизм в науке, идею, согласно которой наши знания всегда несовершенны; и тот и другой использовали эволюционный подход к росту знания и т.д. Позже, К. Поппер все-таки открыл для себя Ч. Пирса, и сам признал, что его мировоззрение по своей сути согласуется с таковым у Ч. Пирса [5, с.20]. Однако К. Поппер, будучи философом XX века, прекрасно понимал в отличие от Ч. Пирса, что наука имеет определенные последствия для человека как личности с должными ей эмоциональными переживаниями.

Более того, К. Поппер видел в этом две проблемы [16, c.222-223]:

1. “Комптоновская проблема", которую он сформулировал как "проблему о влиянии мира абстрактных значений, смыслов (meanings) на человеческое поведение (и, следовательно, на физический мир)

2. "Декартовская проблема" - проблема взаимоотношения духа и тела.

Подобно Ч. Пирсу К. Поппер считает, что законы изменчивы, то есть эволюционируют. Физическая система не является закрытой, то есть она может изменятся под действием другой, ментальной и наоборот. Это значит, что человеческая свобода не просто не обесценивается, но наоборот включается в научное мировоззрение. Создавая теории о мире, мы влияем тем самым на физические процессы, что заставит последние перестроиться. В другой своей книге "Знание и психофизическая проблема" К. Поппер ассимилирует данное предположение со своей концепцией трех миров: мира физических состояний (мир 1), мира ментальных состояний (мир 2) и мира объективного знания, абстрактных значений, смыслов (мир 3).

Однако, возникает вопрос: почему у ученных есть привилегия на поправки в мире 3? Почему мы не можем пойти по пути Р. Рорти и сказать, что у ученных этой привилегии на самом деле нет, так как нет никакой объективности? Здесь К. Поппер разрабатывает свою версию критического здравого смысла, которую для отличия от 
версии Ч. Пирса, можно назвать просвещенным здравым смыслом. К. Поппер также как и Ч. Пирс считает, что здравый смысл является смутным и некритически принятым, он назвал это в целом "фоновым знанием". Однако в отличие от последнего считает, что они могут быть ложными. Для Ч. Пирса здравый смысл не был знанием, которое можно оценивать со стороны как истинное или ложное [1]. Здравый смысл для него был набором верований, которые мы можем лишь принимать или не принимать. Методом же отбора верования служит сомнение. Если я могу сомневаться в своих верованиях, то стоит их пересмотреть, иначе мы просто убеждаемся в их несомненности. Тем не менее, попперовский подход не лишен оснований. Критикуя наивную версию здравого смысла Т. Рида, К. Поппер анализирует понятия “несомненности". Он справедливо замечает, что не существует абсолютной несомненности:

"Держа руки в карманах, я совершенно «уверен», что у меня пять пальцев на каждой из рук, но если жизнь моего лучшего друга зависела бы от истинности этого высказывания, я мог бы (и думаю, что сделал бы это) вынуть руки из карманов, чтобы «вдвойне» убедиться, что уменя каким-то чудом не пропал один из пальщев." [17, с.83].

А раз не существует абсолютной несомненности, то наука просто не может рассматривать здравый смысл как набор несомненных верований. Здравый смысл таким образом является обыденным представлением о мире, которое наука должна преодолеть или изменить. К. Поппер рассматривает здравый смысл лишь как опору для науки, но характерной чертой для него является особый научный метод т.н. фальсификационизм - идея о том, что научная теория является научной если имеет способ, благодаря которому эта теория можем быть опровергнута.

Сьюзан Хаак - явный реципиент идей Ч. Пирса, будет защищать критический здравый смысл, аргументируя это тем, что сам метод фальсификации не применим к самому себе, иначе говоря, он не является сам научной теорией [2, с.49-53]. У науки нет какого-либо привилегированного метода, все методы которые использует наука, существуют не только в ее пределах. Именно, поэтому справедлива цитата А. Эйнтштейна:

"Суть науки не более чем в совершенствовании повседневного мышления [перевод - С. К]" [2, с.47].

Однако С. Хаак, почему-то упускает важность посылок, на которой выстраиваться метод К. Поппера. Для К. Поппера важна не только наука, но и личность. Личность ученного для него была важна даже больше, чем собственно наука, что наблюдается в его книге "Открытое общество и его враги". К. Поппер искал нечто, что могло бы одновременно обосновать объективность наук и романтизировать ученного, придать его деятельности некоторого оттенка творчества.

\section{Зак^ючение}

Проследив развитие концепта здравого смысла, можно выделить 2 проблемы, которые мешают достичь консенсуса:

1. Взаимосвязь здравого смысла и объективности.

2. Взаимосвязь здравого смысла и человеческой повседневности.

Решая проблему (1), правые прагматисты (Пирс, Хаак) забывают про проблему (2). Левые же (Джеймс, Дьюи, Рорти) наоборот. Отличными от них являются К. Поппер и Х. Патнэм. И тот и другой пытались решить обе проблемы, но натолкнулись на противоречия. Попперовская объективность оказывается не такой уж объективной, а патнэмовские идеалы, не таким уж идеальными. В итоге возникает вопрос: что делать?

Чтобы решить эту проблему автор данной работы предлагает несколько шагов.

Во-первых, это критика витгенштейнианской предпосылки Р. Рорти, будто между языком и ощущением нет никакого посредника; будто бы употребление языка есть причина наличия у нас понятий об ощущениях. Дж. Серл справедливо замечает общую проблему для всей ранней аналитической философии, а именно проблему происхождения языка. По мнению философа его предшественники принимали язык как данность, не замечая тот факт, что язык, как и человек имеет естественное происхождение (Searle). Язык сроднен с человеком, а это значит, что те вещи, которые он выражает не находятся в подчинительной связи с ним. Цвета и краски мира не конструируются языком. Они им лишь выделяются просто благодаря тому, что в языке мы оформляем их дискретным образом, в то время как в природе они непрерывны. В природе действительно нет красного как красного, но есть красные краски мира, на которые мы обращаем внимание. Тоже самое и с ощущениями. Иначе говоря, между языком и ощущением посредник все-таки есть и им является до-лингвистическая интенция. Принимая данное положение, мы с необходимостью должны отказаться от той идеи, что истина - это языковая игра.

Во-вторых, нужно также отбросить предрассудок правых прагматистов о том, что сам здравый-смысл можно вскрыть и изменить рациональным методом. Откуда тогда возник сам рациональный метод и рациональность? Левые верно замечают, что здравый смысл как-то связан с человеческим общежитием.

В-третьих, мы должны примерить реалистические и анти-реалистические тезисы двух лагерей. Это достигается введением понятия об ультрареальности. Действительно, субъективность и объективность в продолжительной части времени слиты в едино. Наша реальность 
таким образом конструируема, но это не значит, что под ней ничего нет. Как тогда объяснить взаимодействие между различными народами, в частности между аборигенами и открывателями?

Взаимодействуя друг с другом, мы некоторым образом разрываем тесную взаимосвязь субъективности и объективности. Р. Рорти был прав, говоря, что у нас нет нейтрального словаря (vocabulary) для взаимодействия. Мы не можем общаться с аборигенами на общем языке. Однако, отклоняя витгенштенианские предпосылки, мы прекрасно понимаем, что нас обоих связывает (chaining) что-то общее. Абориген также как и я умирает; абориген также как и я ест, передвигается и имеет собственные намерения и желания. Отличным образом это раскрывается на примере мирного договора и военных действий. Чтобы заключить мирный договор между воюющими сторонами, мы с необходимостью должны найти общую почву, коей по мнению автора данной работы, является ужас собственных действий. Ужасы войны приоткрывают занавес нашей реальности.

Таким образом, объективность не существует как знание, но как схватывание единства вещей и своего собственного существования. Пытаясь формализовать этот здравый смысл, мы так или иначе натыкаемся на ошибки в лице познавательной пропасти. Поэтому правы были Ч. Пирс и К. Поппер, утверждая принцип фаллибилизма, но ошибались в том, что истина всегда однобока.

Автор предлагает рассматривать истину как куб, все стороны которого невозможно видеть одновременно с одного лишь ракурса, однако здравый смысл позволяет нам быть уверенным в том, что этих сторон больше чем всегда видится, и что перед нами действительно куб, а не квадрат или что-то еще.

\section{ЛИТЕРАТУРА}

1. Haack, S., \& Kolenda, K. (1977). Two Fallibilists in Search of the Truth. Proceedings of the Aristotelian Society, Supplementary Volumes, 51, 63-104. http://www. jstor.org/stable/4106816

2. Haack, Susan, Just Say 'No' to Logical Negativism (April 2016). in Karl Raimund

3. Hernández, N. 2017. "Consequences of Rorty's Pragmatism in Science." European Journal of Pragmatism and American Philosophy, no. IX: 2. doi:10.4000/ejpap.1074

4. Johansen, T.K. (2009). Aristotle on the Common Sense, by Pavel Gregoric. Mind, 118(472), 1138-1141. doi:10.1093/mind/fzp120

5. Niiniluoto, I. (1984). Notes on Popper as follower of Whewell and Peirce. In Is Science Progressive? (pp. 18-60). Springer, Dordrecht.

6. Pihlström, S. (2004). Putnam and Rorty on their pragmatist heritage: Re-reading James and Dewey. In Dewey: Modernism, Postmodernism, and Beyond (pp. S-39). Routledge

7. Putnam, Hilary. (1975). The Meaning of «Meaning». University of Minnesota Press, Minneapolis. Retrieved from the University of Minnesota Digital Conservancy

8. Searle, J. R. (2008). What is language: some preliminary remarks (pp. 7-38). De Gruyter Mouton.

9. Витгенштейн Л. Философские исследования // Витгенштейн Л. Философские работы. Ч.1. М., 1994

10. Джохадзе Игорь Давидович (2018). «прагматизм как образ жизни»: Хилари Патнэм и Рут Анна Патнэм о философском наследии Джеймса и Дьюи. Вестник Томского государственного университета. Философия. Социология. Политология, (44), 269-277.

11. Драгалина-Черная. Е. . (2020). Цвета в логическом пространстве Людвига Витгенштейна. Вопросы философии, (6), 146-156. https://doi. org/10.21146/0042-8744-2020-6-146-156

12. Кант И. Соч. В 6 томах. М., 1966. Т.6.

13. Пирс Ч. Начала прагматизма / Перевод с английского В.В. Кирющенко, М.В. Колопотина, послесловие Сухачева В.Ю. — СПб.: Лаборатория метафизических исследований философского факультета СПбГУ; Алетейя, 2000. Т.1 - 318 с.

14. Пирс Ч.П Начала прагматизма / Перевод с английского, предисловие В.В. Кирющенко, М.В. Колопотина, - СПб.: Лаборатория метафизических исследований философского факультета СПбГУ; Алетейя, 2000. Т.2. - 352 с

15. Поппер, Карл Р. Знание и психофизическая проблема: В защиту взаимодействия. / Перевод с англ. — М.: Издательство ЛКИ, 2008. - 256 с.

16. Поппер, Карл Р. Объективное знание: Эволюционный подход. Пер. с англ. / Отв. ред. В.Н. Садовский. Изд. 4-е. — М.:УРСС: ЛЕНАНД, 2022. — 384 с.

17. Поппер Карл Р. Все люди — философы: Как я понимаю философию; Иммануил Кант — философ Просвещения. / Пер. с нем., вступи. статьи и примеч. И.3. Шишкова. Изд. 2-е, стереотипное. - М.: Едиториал УРСС, 2003. - 56 с

18. Рорти Р. Философия и зеркало природы / пер. с англ. В.В. Целищева. - М.: Канон+РООИ “Реабилитация”, 2022. - 368 с., ил.

19. Томас Рид. Исследование человеческого ума на принципах здравого смысла. Пер. с англ. Ю.Е. Милютина, лаборатория метафизических исследований при философском факультете СПбГУ, “АЛЕТЕЙЯ”, Санкт-Петербург. 2000

20. У. Джеймс. Прагматизм. Шиповник, Санкт-Петербург. 1910.

21. Гагинский А.М. 0 смысле бытия и значениях сущего: историко-философские разыскания // Философский журнал| Philosophy Journal. 2016. T. 9. № 3. C. 59-76.

22. Лошаков Руслан Анатольевич Греческая онтология и схоластическая аналогия сущего // Вестник Северного (Арктического) федерального университета. Серия: Гуманитарные и социальные науки. 2006. №1. URL: https://cyberleninka.ru/article/n/grecheskaya-ontologiya-i-sholasticheskaya-analogiya-suschego (дата обращения: 28.11.2021). 